\title{
Comparison of budesonide Turbuhaler with budesonide aqua in the treatment of seasonal allergic rhinitis
}

\author{
William H Yang $M D^{1}$, Jerry Dolovich $M D^{2}$, Michel A Drouin $M D^{1}$, Paul Keith $M D^{2}$, \\ Jennifer Haddon $\mathrm{MSc}^{3}$, Barbara Jennings $\mathrm{PhD}^{3}$ and the Rhinocort Study Group \\ ${ }^{1}$ Section of Allergy and Clinical Immunology, Department of Medicine, University of Ottawa, \\ Ottawa; ${ }^{2}$ Division of Clinical Immunology and Allergy, McMaster University, Hamilton; \\ ${ }^{3}$ Astra Pharma Inc, Mississauga, Ontario
}

\begin{abstract}
WH Yang, J Dolovich, MA Drouin, P Keith, J Haddon, $B$ Jennings. Comparison of budesonide Turbuhaler with budesonide aqua in the treatment of seasonal allergic rhinitis. Can Respir J 1998;5(6):455-460.
\end{abstract}

OBJECTIVE: To compare the effect of budesonide Turbuhaler $400 \mu \mathrm{g} /$ day with budesonide aqua $256 \mu \mathrm{g} /$ day in the treatment of seasonal allergic rhinitis (SAR). Secondarily to ascertain patients' preferences for the two nasal devices and to assess quality of life.

DESIGN: Randomized, multicentre, double-blind, doubledummy, parallel groups study.

SETTING: Private practices and hospital clinics in Ontario, Quebec and Manitoba.

POPULATION: Two hundred and eighty-four out-patients with SAR, who were symptomatic during the ragweed season, volunteered for enrolment (243 randomized).

RESULTS: Mean daily nasal symptom scores were significantly reduced with treatment. There were no statistically significant changes from baseline for eye symptoms. Most patients (more than 80\%) achieved substantial control of their symptoms with budesonide. The most common nasal and non-nasal adverse events for both groups were epistaxis and headache. Turbuhaler was easier to use and more convenient to carry, had less of an unpleasant taste, and caused less nasal irritation than the aqua spray. More than twice as many patients preferred Turbuhaler to the aqua spray (69\% versus $31 \%$ ). Improvement in quality of life from baseline to clinic visits was statistically significant in both groups.

CONCLUSION: Once daily use of $256 \mu \mathrm{g}$ of budesonide aqua and $400 \mu \mathrm{g}$ of budesonide Turbuhaler are equally safe and efficacious in the treatment of SAR. Patients preferred the budesonide powder formulation delivered via Turbuhaler two to one over the aqua formulation.

Key Words: Anti-inflammatory agents, Budesonide, Glucocorticoids, Intranasal symptoms, Seasonal allergic rhinitis, Turbuhaler

Comparaison du budésonide en Turbuhaler et du budésonide en solution aqueuse dans le traitement de la rhinite allergique saisonnière

OBJECTIFS : En premier lieu, comparer l'effet du budésonide en Turbuhaler à $400 \mu \mathrm{g} / \mathrm{j}$ our avec celui du budésonide en solution aqueuse à $256 \mu \mathrm{g} /$ jour dans le traitement de la rhinite allergique saisonnière (RAS). En second lieu, vérifier la préférence des patients entre les deux dispositifs nasaux et évaluer la qualité de vie.

PLAN DE L'ÉTUDE : Étude randomisée, multicentrique, à double insu, avec double placebo et groupes parallèles.

ENDROITS : Cabinets privés et cliniques externes d'hôpitaux en Ontario, au Québec et au Manitoba.

POPULATION : Deux cent quatre-vingt-quatre patients externes atteints de RAS, présentant des symptômes pendant la saison de

voir page suivante 
l'herbe à poux ont accepté de participer (243 ont été randomisés). RÉSULTATS : Les scores moyens quotidiens de symptômes nasaux ont été réduits de façon significative grâce au traitement. Aucun changement significatif sur le plan statistique n'a été noté par rapport aux valeurs de base pour les symptômes oculaires. Le budésonide a permis d'atteindre une bonne maîtrise des symptômes chez la plupart des patients (plus de $80 \%$ ). Les manifestations indésirables nasales et non nasales les plus fréquentes pour les deux groupes étaient l'épistaxis et les céphalées. Le Turbuhaler était le dispositif le plus facile à utiliser et le plus commode à emporter; les patients utilisant le Turbuhaler se sont plaints moins souvent de goût désagréable et d'irritation nasale que les patients utilisant la solution aqueuse. Plus du double des patients ont préféré le Turbuhaler par rapport au vaporisateur de solution aqueuse (69\% contre $31 \%$ ). L'amélioration de la qualité de vie entre les valeurs de base et les visites à la clinique était significative sur le plan clinique pour les deux groupes.

CONCLUSION : Le budésonide à $256 \mu \mathrm{g}$ une fois par jour en solution aqueuse est aussi sûr et efficace que le budésonide à $400 \mu \mathrm{g}$ une fois par jour en Turbuhaler pour le traitement de la RAS. Les patients ont préféré la préparation de poudre de budésonide libérée par Turbuhaler dans un rapport de 2:1 par rapport à la préparation aqueuse.
$\mathrm{M}$ any treatments exist for the control of symptoms of seasonal allergic rhinitis (SAR). Topical glucocorticosteroids (GCS) such as budesonide have been shown to be effective as anti-inflammatory agents in the treatment of SAR (1-3). Generally once or twice daily administration of inhaled GCS in both aqueous (4) and dry powder (5) formulations has been shown to be effective in treating adults with allergic rhinitis.

For this indication, budesonide is manufactured as an aqueous spray, budesonide aqua (aqua) $64 \mu \mathrm{g} / \mathrm{dose}$. Additionally, there is budesonide Turbuhaler $100 \mu \mathrm{g} / \mathrm{dose}$, a relatively new, dry powder, multiple-dose inhaler that is actuated by inhalation via the nose. Only pure drug, with no chlorofluorocarbons or carrier agents, is delivered via Turbuhaler. Nevertheless, there has been some concern about the usefulness of the dry powder inhaler in relieving nasal congestion.

Comparability between the pure dry powder inhaler, Turbuhaler, and the aqueous formulation has not been established with respect to efficacy, safety or patient preference in ragweed-induced allergic rhinitis.

With Turbuhaler, there is some retention of the drug in the nasal applicator (36\% of the metered dose or $144 \mu \mathrm{g} / 400 \mu \mathrm{g}$ dose), whereas the entire dose is delivered from the pump of the water suspension. Thus, the appropriate comparison is Turbuhaler $400 \mu \mathrm{g}(256 \mu \mathrm{g}$ delivered dose) once daily versus aqua $256 \mu \mathrm{g}$ once daily. The primary objective of this study was to compare the effect of budesonide as a pure dry powder $400 \mu \mathrm{g} /$ day with budesonide as an aqueous suspension $256 \mu \mathrm{g} /$ day in the treatment of ragweed-induced SAR. The secondary objectives were to ascertain the patients' preferences for the two nasal devices used in this study, and to assess the patients' quality of life (QoL) before and during budesonide therapy.

\section{PATIENTS AND METHODS}

This trial was of a randomized, multicentre, double-blind (during the treatment phase), double-dummy, parallel groups design. The protocol was approved by the ethics review boards of participating hospitals or universities, and was carried out in accordance with the Helsinki Declaration.

Patients had three clinic visits at baseline, randomization and end of treatment. At visit one, nine centres across Canada (five in Ontario, three in Quebec and one in Manitoba) enrolled a total of 284 patients (Figure 1) after signed, informed consent was obtained. The patients were required to have a clinical history of ragweed-induced allergic rhinitis (including rhinoconjunctivitis). Ragweed sensitivity was confirmed by a positive allergy skin prick test, $3 \mathrm{~mm}$ or greater wheal to a standard mixed ragweed extract (Giant and Short, Bencard Allergy Labs at a concentration of 1:20). Sensitivity to other pollens was not tested because this was presumed to be equally distributed among the groups. Patients were required to have had rhinitis symptoms in at least one previous ragweed season. Then, during a one-week baseline period when ragweed was present in the air, all subjects recorded their symptoms while using placebos of aqua and Turbuhaler.

At visit two, 243 eligible patients (111 males and $132 \mathrm{fe}-$ males, aged 19 to 74 years) were randomized into the fourweek study. Patients were randomly assigned to one of four treatment groups. Only one of the delivery devices they used contained the active medication (ie, one active device and one placebo device). The order of use was also balanced: group A took placebo aqua before active Turbuhaler $(n=63)$; group B took active Turbuhaler before placebo aqua $(n=59)$; group $C$ took active aqua before placebo Turbuhaler $(\mathrm{n}=60)$; and group $\mathrm{D}$ took placebo Turbuhaler before active aqua $(\mathrm{n}=61)$.

Patients were instructed how to use the study devices, and the first dose was administered under supervision. They were also given written instructions for the use of the devices including the statement that they were to be used in the morning upon rising.

All patients were required to start treatment within four days of the early part of the ragweed pollination period (August 17 to 20,1993). Treatment was to be completed by September 20, 1993. All patients were contacted by telephone by a member of the clinic's research team during the first week of September (visit 2.5) to ensure that the patients had completed their self-administered Rhinoconjunctivitis Quality of Life Questionnaire (1) (RQLQ).

Patients completed a daily evaluation of their nasal symptoms (blocked nose, runny nose and sneezing) and eye symptoms. They assessed these symptoms on a scale of 0 to 3 ( $0=$ absent, $1=$ mild, $2=$ moderate, $3=$ severe $)$. Patients were required to have at least two nasal symptoms with scores higher than or equal to 1 (mild) during at least five days of the baseline period. At their third and final visit, patients were asked to make an overall assessment evaluating the ability of the therapy to control their nasal symptoms. They used a scale of 0 (total control over symptoms) to 4 (symptoms were aggravated) for this purpose. 


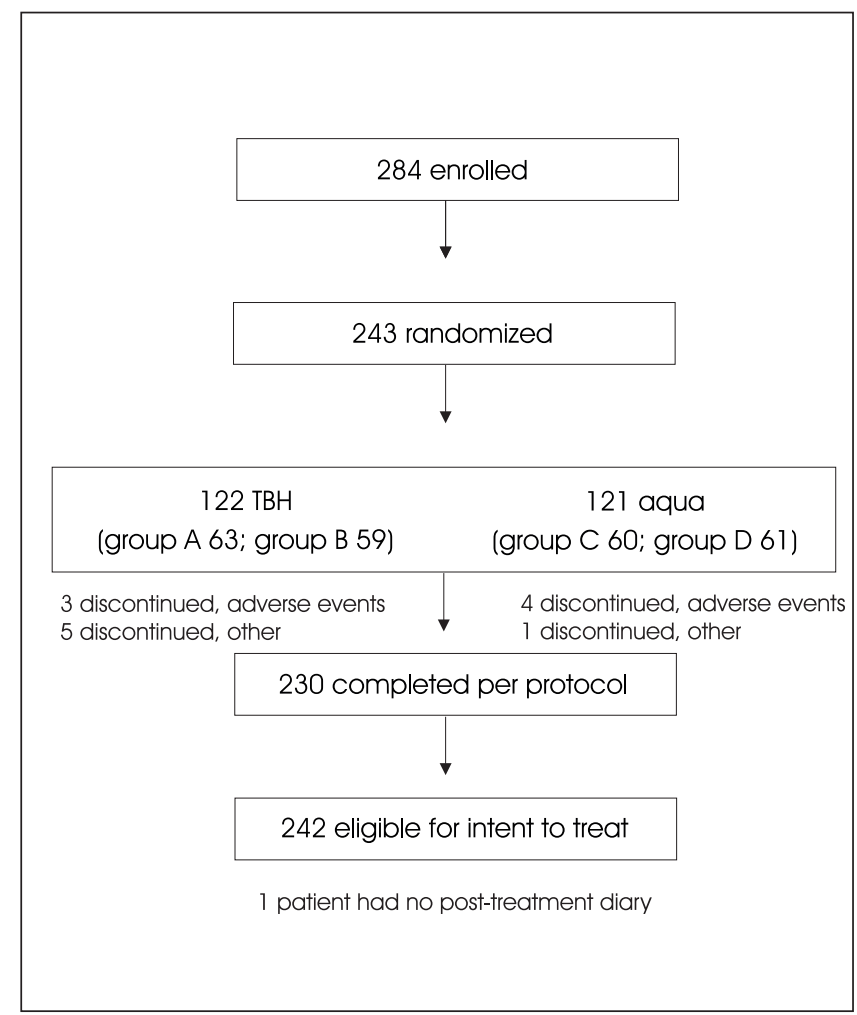

Figure 1) Disposition of patients in Turbuhaler (TBH) versus aqua budesonide study. Group A took placebo aqua before active Turbuhaler (n=63); group B took active Turbuhaler before placebo aqua $(n=59) ;$ group $C$ took active aqua before placebo Turbuhaler $(n=60)$; and group D took placebo Turbuhaler before active aqua $(n=61)$

QoL was assessed by means of the RQLQ before treatment, midtreatment (visit $2.5=$ at home), and after treatment at visit 3 .

A patient preference questionnaire was completed at the end of treatment to compare the two nasal devices used in the study. Five questions were asked about both devices to evaluate ease of use, convenience to carry, unpleasant taste, hoarseness and nasal irritation. The results of the questionnaire were derived from the patients' scoring of a $100 \mathrm{~mm}$ visual analogue scale $(\mathrm{VAS})(0 \mathrm{~mm}=$ very bad to $100 \mathrm{~mm}=$ very good). Patients were then asked which device they would prefer to use if given a choice.

Patient compliance with respect to study drug administration was estimated by counting the remaining doses in Turbuhaler and by weighing the aqua bottles before and after treatment.

Adverse events were recorded by asking a standard question at each visit, "Have you experienced any health problems or other symptoms not usually related to your allergic rhinitis since the last visit?".

Statistics: The results reported are from the intention-totreat analysis. The group mean of the individual symptom scores was calculated over the one-week baseline and the four-week treatment periods. A mean of the combined nasal symptom scores was also calculated. The change in these mean scores from baseline was compared among treatments

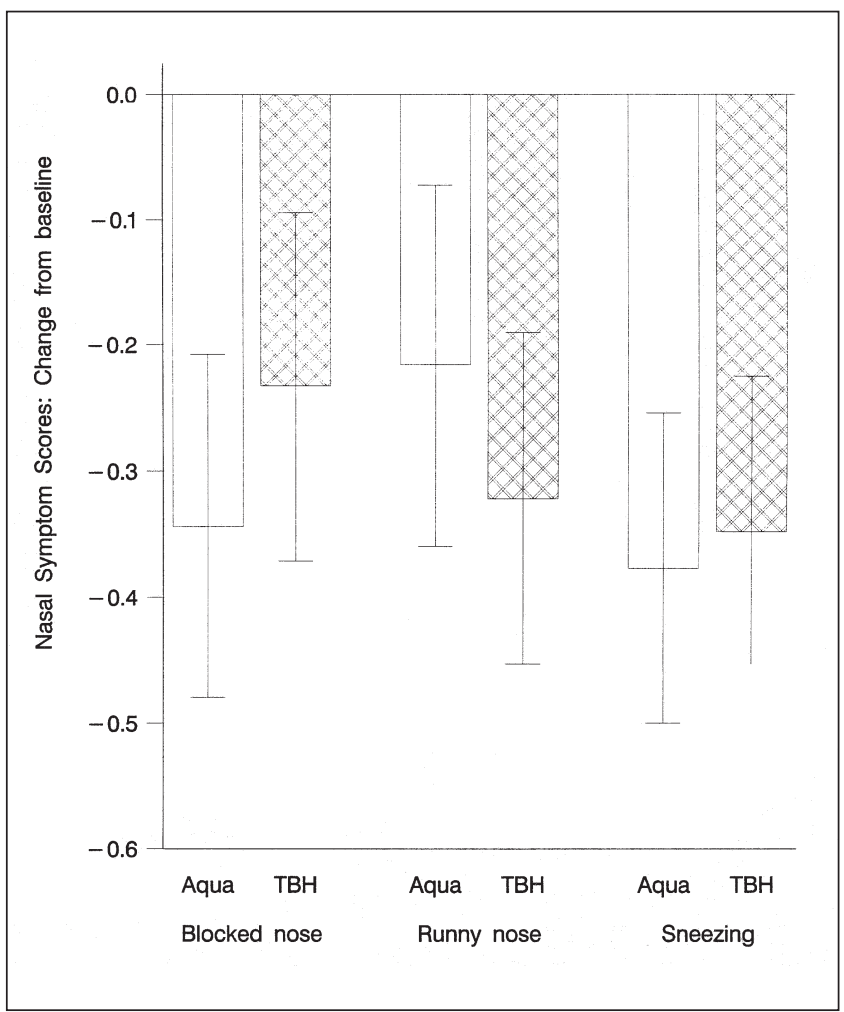

Figure 2) Change from baseline for nasal symptom scores (blocked nose, runny nose and sneezing) including the $95 \%$ confidence limit. Aqua Budesonide via aqueous spra; TBH Budesonide via Turbuhaler

by ANOVA with factors of treatment group and centre and by an analysis of covariance (ANCOVA) with adjustment for the baseline score. A paired $t$ test was used to analyze change from baseline within each group.

The global assessments of treatment effect, patient compliance and eye symptom scores were analyzed by ANOVA. The data from the RQLQ questionnaires were analyzed by repeated measures of multivariate analysis of variance (MANOVA), and the paired data (VAS score on both devices) from the patient preference surveys were analyzed by paired $t$ tests.

In all tests of significance, two-tailed alternatives were used. Differences of $\mathrm{P}<0.05$ were considered to be statistically significant.

The predetermined sample size of 228 patients ( 250 in total were to be enrolled to account for a possible $10 \%$ dropout rate) would provide a $90 \%$ power (alpha $=0.05$, two-tailed) to detect a treatment difference of 0.3 in individual symptom scores. The power estimate was made assuming a SD of 0.7 .

The SAS software package (SAS Institute, North Carolina), version 6.08/VAX was used for the data analysis.

\section{RESULTS}

The groups of patients were comparable at baseline with respect to demographics, nasal symptoms, RQLQ and ragweed sensitivity (Table 1). As well, compliance with study 
TABLE 1

Patient demographics by treatment group (mean \pm SD)

\begin{tabular}{lcc}
\hline & Turbuhaler & Aqua \\
\hline Total & $121^{*}$ & 121 \\
Male/Female & $58 / 63$ & $52 / 69$ \\
Age (years) & $35.4 \pm 11.5$ & $36.6 \pm 11.6$ \\
Weight (kg) & $74.9 \pm 17.1$ & $73.1 \pm 16.0$ \\
Height (cm) & $169.8 \pm 9.3$ & $169.5 \pm 12.9$ \\
Ragweed skin test (mm) & $8.7 \pm 4.4$ & $8.7 \pm 4.2$ \\
Combined nasal scores & $3.17 \pm 1.76$ & $3.23 \pm 1.77$ \\
Overall Rhinoconjunctivitis Quality of Life Questionnaire scores & $1.97 \pm 1.13$ & $2.03 \pm 1.17$ \\
\hline
\end{tabular}

${ }^{*}$ Efficacy data were only available for 121 patients

TABLE 2

Overall assessment of treatment efficacy after therapy with budesonide as measured by symptom control

\begin{tabular}{lccr}
\hline & Turbuhaler $\mathbf{n}(\%)$ & Aqua $\mathbf{n}(\%)$ & Total $\mathbf{n}(\%)$ \\
\hline Total control & $21(18)$ & $29(24)$ & $50(21)$ \\
Substantial control & $71(59)$ & $70(58)$ & $141(59)$ \\
Minor control & $20(17)$ & $17(14)$ & $37(15)$ \\
No control & $8(7)$ & $5(4)$ & $13(5)$ \\
All & $120(100)$ & $121(100)$ & $241(100)$ \\
\hline
\end{tabular}

medication during the treatment phase was comparable between the groups: $99.4 \%$ Turbuhaler and $101.8 \%$ aqua.

The change from baseline for daily nasal symptom scores was not significantly different among the treatment groups (blocked nose $\mathrm{P}=0.26$, runny nose $\mathrm{P}=0.26$, and sneezing $\mathrm{P}=0.75)$. The nasal symptom scores were significantly improved with both treatments $(0.0001<\mathrm{P}<0.044)$ compared with the placebo baseline except for the symptom of runny nose when the active aqua was used before placebo Turbuhaler $(0.05<\mathrm{P}<0.10)$.

The initial plan for the statistical analysis did not include the baseline as a covariate. Upon viewing the results, it was added to the analysis and was found to be significant $(\mathrm{P}<0.0001)$. However, the addition of baseline as a covariate in the analysis did not reveal a treatment difference. In addition, the centre effect for combined nasal symptoms was not significant, but it was significant for the runny nose symptom $(\mathrm{P}=0.034)$. The change from baseline for eye symptoms was not statistically significant within or between groups. Furthermore, there were no significant order or sequence differences found in the comparisons of any of the symptoms. Eighty per cent of the patients achieved substantial (59\%) or total control $(21 \%)$ of their symptoms with budesonide (Table 2).

The patient preference questionnaire showed that Turbuhaler was thought to be easier to use $(\mathrm{P}=0.017)$ and more convenient to carry $(\mathrm{P}=0.002)$. It was perceived to have less of an unpleasant taste $(\mathrm{P}=0.0001)$ and rated to cause less nasal irritation than the aqua spray $(\mathrm{P}=0.001)$. The degree of hoarseness was not significantly different between the groups. The overall device preference revealed that more than twice as many patients preferred Turbuhaler to the aqua spray (69\% versus $31 \%)$.
There was no statistically significant difference in RQLQ between the treatment groups (Table 3). However, there was a statistically significant improvement in RQLQ from baseline to clinic visits in both groups for all seven domains, that is, activities, emotional, eye, nasal, nonhay fever symptoms, practical, sleep and overall QoL $(\mathrm{P}<0.002$ across all domains).

The frequency of adverse events was similar for the Turbuhaler and aqua groups. The most common, non-nasal adverse event reported was headache, 17 patients (13.9\%) in the Turbuhaler group and 18 patients $(14.9 \%)$ in the aqua group. The most common nasal adverse event was epistaxis: six patients $(4.9 \%)$ in the Turbuhaler group and seven patients $(5.8 \%)$ in the aqua group. Only one serious adverse event was reported: a patient was hospitalized for acute appendicitis and had a full recovery.

\section{DISCUSSION}

This study demonstrates the comparable effects and safety of budesonide aqua $256 \mu \mathrm{g}$ and budesonide Turbuhaler $400 \mu \mathrm{g}$ once daily in the treatment of ragweed-induced allergic rhinitis. The improvement in mean daily nasal symptom scores of patients with SAR upon treatment with budesonide agrees with previously published studies in patients with grass pollen allergies treated for four weeks $(2,3)$ and in patients with hay fever treated for three weeks (4). The lack of a statistically significant change from baseline for the runny nose symptom in treatment group $\mathrm{C}$ (active aqua/placebo Turbuhaler) may be due to the initial low baseline score leaving little room for improvement. There appears to be no other clinical explanation for this finding because there were no significant treatment differences among groups.

Data concerning eye symptoms were collected in the pa- 
TABLE 3

Quality of life with budesonide treatment

\begin{tabular}{|c|c|c|c|c|c|c|}
\hline \multirow[b]{2}{*}{ Domain } & \multirow[b]{2}{*}{ Visit } & \multicolumn{2}{|c|}{ Turbuhaler } & \multicolumn{2}{|c|}{ Aqua } & \multirow[b]{2}{*}{$\mathbf{P}^{*}$} \\
\hline & & $\mathbf{n}$ & Mean (SD) & $\mathbf{n}$ & Mean (SD) & \\
\hline \multirow[t]{3}{*}{ Activities } & 2 & 120 & $2.28(1.33)$ & 120 & $2.36(1.51)$ & \\
\hline & 2.5 & 114 & $1.64(1.27)$ & 120 & 1.49 (1.32) & \\
\hline & 3 & 118 & $1.12(1.06)$ & 120 & $1.06(1.20)$ & 0.64 \\
\hline \multirow[t]{3}{*}{ Emotional } & 2 & 121 & $1.70(1.39)$ & 120 & $1.83(1.40)$ & \\
\hline & 2.5 & 115 & $1.26(1.20)$ & 120 & $1.25(1.22)$ & \\
\hline & 3 & 119 & $0.92(0.95)$ & 120 & $0.85(1.10)$ & 0.76 \\
\hline \multirow[t]{3}{*}{ Eye } & 2 & 121 & $1.89(1.35)$ & 121 & $1.98(1.45)$ & \\
\hline & 2.5 & 116 & $1.63(1.39)$ & 121 & $1.73(1.47)$ & \\
\hline & 3 & 119 & $1.22(1.19)$ & 120 & $1.17(1.24)$ & 0.83 \\
\hline \multirow[t]{3}{*}{ Nasal } & 2 & 121 & $2.75(1.39)$ & 121 & $2.63(1.31)$ & \\
\hline & 2.5 & 116 & $1.70(1.23)$ & 121 & $1.56(1.16)$ & \\
\hline & 3 & 119 & $1.41(1.08)$ & 120 & $1.19(1.04)$ & 0.58 \\
\hline Non- & 2 & 121 & $1.49(1.19)$ & 121 & $1.68(1.30)$ & \\
\hline \multirow[t]{2}{*}{ hay fever } & 2.5 & 117 & $1.14(1.01)$ & 121 & $1.29(1.16)$ & \\
\hline & 3 & 119 & $0.92(0.96)$ & 120 & $0.88(1.06)$ & 0.43 \\
\hline Practical & 2 & 121 & $2.58(1.46)$ & 121 & $2.41(1.43)$ & \\
\hline \multirow[t]{2}{*}{ problems } & 2.5 & 116 & $1.67(1.21)$ & 121 & $1.71(1.36)$ & \\
\hline & 3 & 119 & $1.33(1.07)$ & 120 & $1.25(1.19)$ & 0.53 \\
\hline \multirow[t]{3}{*}{ Sleep } & 2 & 121 & $1.60(1.43)$ & 121 & $1.65(1.44)$ & \\
\hline & 2.5 & 117 & $1.14(1.28)$ & 121 & $0.96(1.05)$ & \\
\hline & 3 & 119 & $0.81(1.08)$ & 120 & $0.73(1.05)$ & 0.48 \\
\hline \multirow[t]{3}{*}{ Overall RQLQ } & 2 & 121 & $1.97(1.13)$ & 121 & $2.03(1.17)$ & \\
\hline & 2.5 & 117 & $1.41(1.01)$ & 121 & $1.42(1.09)$ & \\
\hline & 3 & 119 & $1.09(0.91)$ & 120 & $1.01(0.97)$ & 0.90 \\
\hline
\end{tabular}

${ }^{\star} P$ for treatment difference. RQLQ Rhinoconjunctivitis Quality of Life Questionnaire

tient diaries and in the RQLQ questionnaires. Analysis showed a discordance in the results. The higher score on the RQLQ questionnaire may reflect a less accurate recall of symptoms at the time of instrument completion (recall bias) (6) or variability in reporting due to social desirability (7). However, because budesonide has little effect on eye symptoms, this finding is not considered to be pertinent. The overall improvement in QoL observed while the patients were on budesonide during the ragweed season is similar to the results from the same type of study in patients with perennial rhinitis published by Juniper and colleagues (8) but of a much smaller magnitude.

The favourable assessment of overall treatment outcome shown by this study was also observed in a grass pollen study reported by Pedersen et al (9). They found that patients treated with budesonide also obtained at least substantial control of their symptoms.

As was expected for this type of therapeutic intervention, the adverse events were similar between the two groups and similar to other studies of this nature.

It was suggested that patients receiving the active dry powder first might have less of an improvement in their symptom of blocked nose because the dry powder could not penetrate the swollen nasal membrane or would possibly be washed away. However, this was not a concern because com- parable improvement was observed in all treatment groups. Thus, patients with a blocked nose can use Turbuhaler to achieve symptom control.

Ideally, a crossover study design might have been more suitable for the patient preference assessment, but a seasonal study does not lend itself to this type of design.

The patients' explanations for their device preferences demonstrate the dichotomy of the issue. Some patients like to know that they are getting the medication by sensing the drug while others do not like to feel anything when taking their drugs.

There were no centre effects for blocked nose and sneezing, and there was only a marginal significance for runny nose, which could have occurred by chance. Therefore, it is likely that symptoms were the same for all the centres.

From a clinical point of view, the patients' greater preference for the dry powder over the aqua formulation does not reflect the number of prescriptions written (four aqua to one Turbuhaler, personal communication). This might reflect the patients' bias towards the relatively new Turbuhaler device used in the study. On the other hand, the lower usage in practice may be due to the perception by patients and physicians that Turbuhaler may be less effective due to poorer distribution of dry powder. Consequently, when prescribing, it is recommended that the patient's preference for the water-based 
or dry powder treatment be sought to ensure optimal compliance. This is particularly important if the patient does not like the taste or irritation that may be encountered when using an aqueous product.

In summary, once daily use of $256 \mu \mathrm{g}$ of budesonide aqua or $400 \mu \mathrm{g}$ of budesonide Turbuhaler should be considered clinically interchangeable. Patients preferred Turbuhaler two to one over aqua.

ACKNOWLEDGMENTS: The Rhinocort study group includes J Bourbeau MD, McGill University, Montreal, Quebec; M Briscoe MD and J Day MD, Queen's University, Kingston, Ontario; CW Frankish MD, University of Ottawa, Ottawa, Ontario; J Mazza MD and W Moote MD, The University of Western Ontario, London, Ontario; J Paradis MD, University of Montreal, Montreal, Quebec; M Rouleau MD, Laval University, Ste-Foy, Quebec; D Thomson MD, McGill University, Montreal, Quebec; RJ Warrington MD, University of Manitoba, Winnipeg, Manitoba. We are grateful for the statistical assistance provided by Joanna Lee MMath of Astra Pharma Inc, Mississauga, Ontario.

\section{REFERENCES}

1. Juniper EF, Guyatt GH. Development and testing of a new measure of health status for clinical trials in rhinoconjunctivitis. Clin Exp Allergy 1991;21:77-83.

2. Pedersen B, Larsen BB, Dahl R, Lindqvist N, Mygind N. Powder administration of pure budesonide for the treatment of seasonal allergic rhinitis. Allergy 1991;46:582-7.

3. Agertoft L, Wolthers OD, Fuglsang G, Pedersen S. Nasal powder administration of budesonide for seasonal rhinitis in children. Pediatr Allergy Immunol 1993;4:152-6.

4. Bhatia M, Campbell LM, Ross JRM, Taylor MD, Peers EM, Richardson PDI. Intranasal budesonide once daily in seasonal allergic rhinitis. Curr Med Res Opin 1991;12:287-95.

5. Andersson M, Lindqvist N, Svensson C, Ek L, Pipkorn U. Dry powder inhalation of budesonide in allergic rhinitis. Clin Otolaryngol 1993;18:30-3.

6. Sackett DL. Bias in analytic research. J Chron Dis 1979;32:51-63.

7. Edwards AL. The Social Desirability Variable in Personality Assessments and Research. New York: Dryden, 1957.

8. Juniper EF, Guyatt GH, Andersson B, Ferrie PJ. Comparison of powder and aerosolized budesonide in perennial rhinitis: validation of rhinitis quality of life questionnaire. Ann Allergy 1993;70:225-30.

9. Pedersen B, Bundgaard LB, Dahl R, Hedbys L, Mygind N. Budesonide powder administration for the treatment of grass-pollen-induced allergic rhinitis. Allergy 1994;49:855-60. 


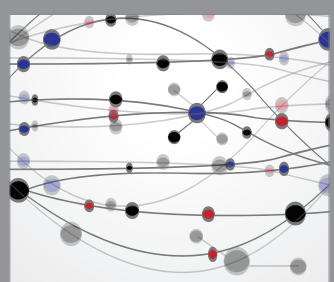

The Scientific World Journal
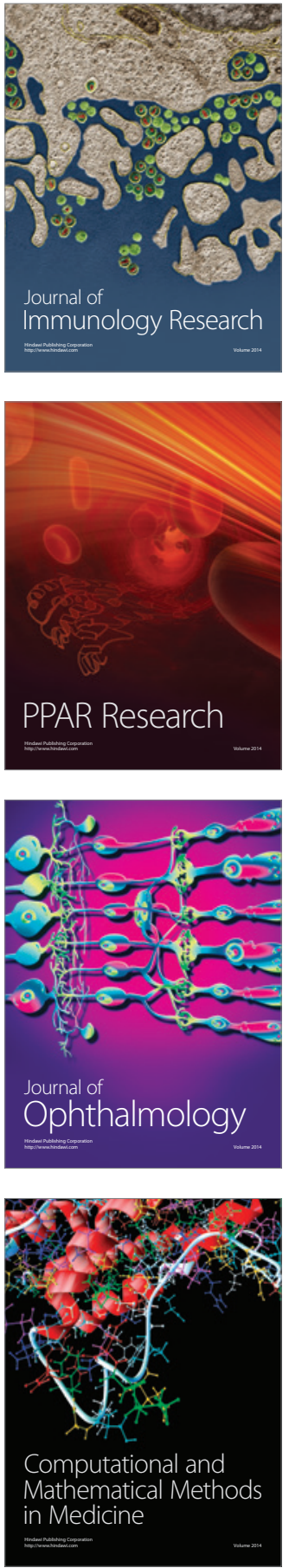

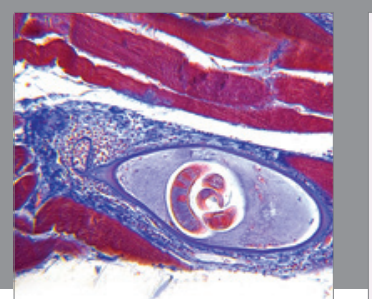

Gastroenterology Research and Practice

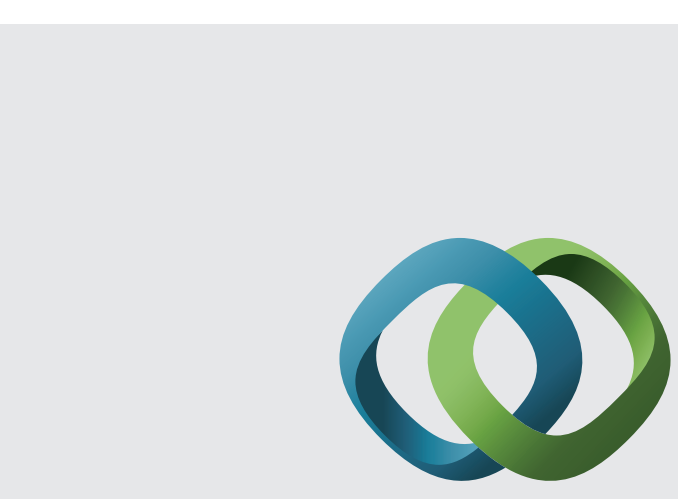

\section{Hindawi}

Submit your manuscripts at

http://www.hindawi.com
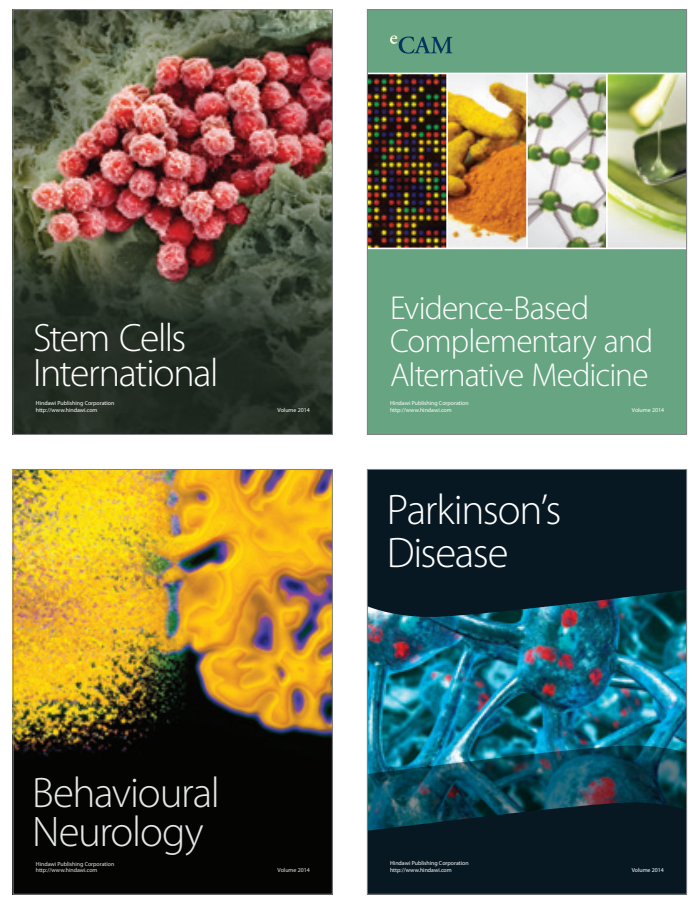
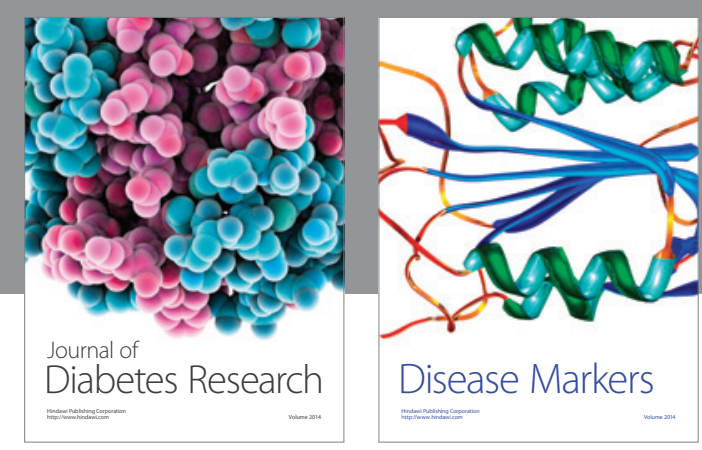

Disease Markers
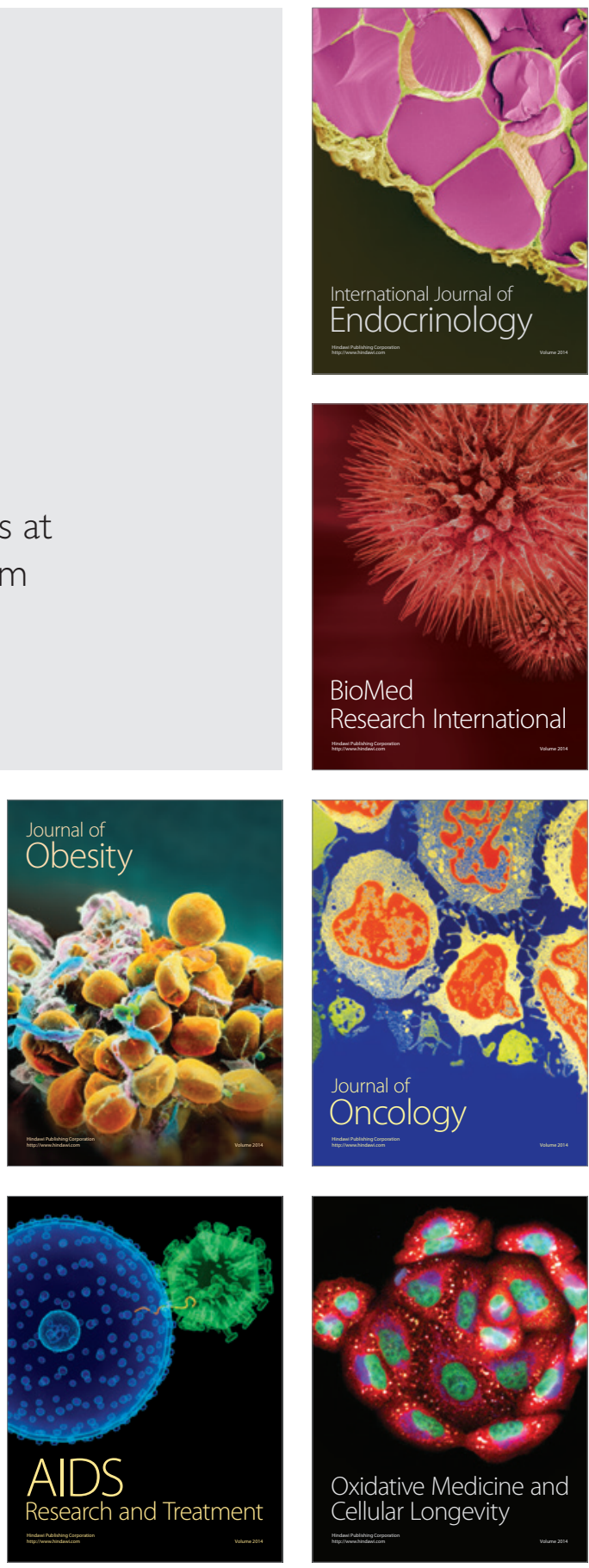